\title{
Anthracnose Fungi with Curved Conidia, Colletotrichum spp. belonging to Ribosomal Groups 9-13, and Their Host Ranges in Japan
}

\author{
Toyozo SATO $^{1 *}$, Jouji MORIWAKI ${ }^{2}$ and Shigeru KANEKO ${ }^{1}$ \\ ${ }^{1}$ Genetic Resources Center, National Institute of Agrobiological Sciences \\ (Tsukuba, Ibaraki 305-8602, Japan) \\ ${ }^{2}$ Horticulture Research Division, NARO Kyushu Okinawa Agricultural Research Center, National \\ Agriculture and Food Research Organization \\ (Kurume, Fukuoka 839-8503, Japan)
}

\begin{abstract}
Ninety fungal strains with falcate conidia belonging to Colletotrichum spp. classified into the ribosomal groups 9-13 (the RG 9-13 spp.) and preserved at the NIAS Genebank, Japan were re-identified based on molecular phylogenetic analysis of the internal transcribed spacer (ITS) region of the rRNA gene, sequences of the glyceraldehyde 3-phosphate dehydrogenase, chitin synthase 1, histone3, and actin genes, and partial sequences of $\beta$-tubulin-2 (TUB2) genes, or by BLASTN searches with TUB2 gene sequences. Seventy strains were reclassified into nine recently revised species, C. chlorophyti, $C$. circinans, C. dematium sensu stricto, C. lineola, C. liriopes, C. spaethianum, C. tofieldiae, C. trichellum and C. truncatum, whereas 20 strains were grouped into four unidentified species. RG 9, 10 and 12 corresponded to the $C$. spaethianum, C. dematium and C. truncatum species complex, respectively, while RG 11 and 13 agreed with $C$. chlorophyti and C. trichellum, respectively. Phylograms derived from a six-locus analysis and from TUB2 single-locus analysis were very similar to one another with the exception of the association between $C$. dematium s. str. and $C$. lineola. Thus, TUB2 partial gene sequences are proposed as an effective genetic marker to differentiate species of RG 9-13 in Japan except for $C$. dematium s. str. and $C$. lineola. Thirty-two plant species were identified as new hosts for seven of the species found in this study except for $C$. circinans and $C$. trichellum; and two unidentified species. Colletotrichum chlorophyti, C. lineola, C. liriopes, C. spaethianum, and C. truncatum were regarded as polyphagous, whereas $C$. trichellum and Colletotrichum sp. (Ra), designated tentatively in this study, appeared to have specific pathogenicity to single hosts, Hedera rhombea and Raphanus sativus var. hortensis, respectively. Conidial curvature properties, "outer curvature," "inner curvature" and "height/width ratio" successfully represented conidial shape parameters. Conidial curvature properties of the species in RG 9, 10 and 12 were found to correlate with the species complexes.
\end{abstract}

Discipline: Agricultural Environment

Additional key words: $\beta$-tubulin-2, conidial curvature properties, molecular phylogenetic analyses, re-identification, species complex

\section{Introduction}

The genus Vermicularia Tode (1790) was established for anthracnose fungi with falcate conidia and setae in acervuli. More than 280 species have been described with nearly every host plant identified (Anonymous 2014). More species with falcate conidia were also described as species in Colletotrichum Corda (1831). Since Arx (1957) synonymized many Vermicularia as well as Colletotrichum species with Colletotrichum graminicola (Ces.) G.W. Wilson and Colletotrichum dematium (Pers.) Grove in addition to its three forma based on morphology, C. graminicola and C. dematium have been regarded as representatives of pathogens on the Poales grasses and other plants, respectively (Arx 1981, 1987, Sutton 1980, 1992). More than 230 strains of Colletotrichum in Japan, including those with falcate conidia and setae, were classified into 20 ribosomal groups (RG) based on molecular phylogenetic analyses of the

This paper reports results obtained in the NIAS Genebank project sponsored by the Ministry of Agriculture, Forestry and Fisheries, Japan. *Corresponding author: e-mail s1043@affrc.go.jp

Received 24 October, accepted 3 April 2015. 
internal transcribed spacer (ITS) region of the rRNA gene (Moriwaki et al. 2002). This analysis showed that six and three species were closely related to C. graminicola and $C$. dematium, respectively. The latter three species, Colletotrichum circinans (Berk.) Voglino, Colletotrichum truncatum (Schwein.) Andrus \& W. D. Moore, and Colletotrichum trichellum (Fr.) Duke, were placed on blanches of RG 10, 11 and 13 in the phylogenetic tree, respectively, while strains of $C$. dematium were classified into both RG 9 and 12. These species belonging to ribosomal groups 9-13 have been tentatively designated as "the RG 9-13 spp." in this study. After Moriwaki et al. (2002), strains pathogenic to the Poales grasses and that are related to C. graminicola were re-classified into 14 species based on a molecular phylogenetic analysis with the ITS, the DNA lyase gene (Apn2), the mating type Mat1-2 (Mat1/Apn2) gene and the manganese superoxide dismutase gene (Sod2) (Crouch et al. 2009). Conversely, strains pathogenic to other plants and related to $C$. dematium were examined based on a molecular phylogenetic analysis with six genes/regions as described below and re-classified into 20 species, including two previously undescribed species (Damm et al. 2009).

Approximately 40 and 90 strains putatively belonging to the C. graminicola species complex and the RG 9-13 spp., respectively, are preserved at the NIAS Genebank, National Institute of Agrobiological Sciences, Japan. Accessions in RG 9-13 spp. are more important economically in Japan because they contain numerous horticultural and food crop pathogens (The Phytopathological Society of Japan \& National Institute of Agrobiological Science 2012). Thus, in order to appropriately control anthracnose caused by these species, it is important that we re-identify these fungi based on the latest methods of molecular phylogenetic analysis and clarify host ranges and morphological differences among species. We, therefore, re-identified a number of Japanese strains belonging to RG 9-13 according to the method described by Damm et al. (2009) to characterize the distribution of the species revised by Damm et al. (2009) and their host plants. The geometry of conidial morphology, especially the curvature of conidia, was also examined to quantify the morphological characteristics of the re-identified species.

\section{Materials and Methods}

\section{Molecular phylogenetic analyses and re-identifica- tion of strains}

Eighty-three strains belonging to RG 9-13 preserved at the NIAS Genebank (Table 1) were re-identified based on phylogenetic analyses using the ITS region of the rRNA gene, sequences of the glyceraldehyde 3-phosphate dehydrogenase (GAPDH), chitin synthase 1 (CHS-1), histone3 (HIS3) and actin (ACT) genes, and partial sequences of the $\beta$-tubulin-2 (TUB2) genes. Genomic DNA extracted according to the procedure described by Moriwaki et al. (2002) was used as a template for the following polymerase chain reaction (PCR) analyses. ITS, GAPDH, CHS-1, HIS3, ACT and TUB2 genes were amplified and sequenced using the primer pairs ITS5 \& ITS4 (White et al. 1990), GDF1 \& GDR1 (Guerber et al. 2003), CHS-354R \& CHS-79F (Carbone \& Kohn 1999), CYLH3F \& CYLH3R (Crous et al. 2004), ACT-512F \& ACT-783R (Carbone \& Kohn 1999) and T1 (O’Donnell \& Cigelnik 1997) \& Bt2b (Glass \& Donaldson 1995), respectively. Each gene region was amplified with Taq polymerase (TaKaRa, Otsu, Japan) in a GeneAmp 9700 (Applied Biosystems, Foster City, CA, USA). Cycling conditions for amplification of ITS were $94^{\circ} \mathrm{C}$ for $3 \mathrm{~min}$, followed by 35 cycles of $94^{\circ} \mathrm{C}$ for $30 \mathrm{sec}-$ $55^{\circ} \mathrm{C}$ for $1 \mathrm{~min}-72^{\circ} \mathrm{C}$ for $1 \mathrm{~min}$, and a final step at $72^{\circ} \mathrm{C}$ for $5 \mathrm{~min}$. Conditions for the remaining five genes were $94^{\circ} \mathrm{C}$ for $5 \mathrm{~min}$, followed by 40 cycles of $94^{\circ} \mathrm{C}$ for $30 \mathrm{sec}-52^{\circ} \mathrm{C}$ for $30 \mathrm{sec}-72^{\circ} \mathrm{C}$ for $30 \mathrm{sec}$, and a final step at $72^{\circ} \mathrm{C}$ for 7 min. PCR products were purified using a QIAquick PCR Purification kit (Qiagen, Chatsworth, CA, USA) and were sequenced directly with the BigDye Terminator v3.1 Cycle Sequencing kit (Applied Biosystems). Sequencing reactions were conducted according to the manufacturer's instructions. Extension products were analyzed on an ABI PRISM 3730 DNA Analyzer (Applied Biosystems, Foster City, CA, USA) according to the manufacturer's instructions. All sequences were uploaded to the database, "Microorganism Search System", NIAS Genebank (http://www.gene.affrc. go.jp/databases-micro_search_en.php).

For phylogenetic analyses, sequence data of the ITS region and the GAPDH, CHS-1, HIS3, ACT and TUB2 gene sequences for the 83 strains examined in this paper, as well as 22 strains comprising an additional 18 species revised by Damm et al. (2009) downloaded from DDBJ/ EMBL/GenBank databases, were included as references (Table 2). Sequences for strains of Glomerella lindemuthiana Shear (Colletotrichum lindemuthianum (Sacc. \& Magnus) Briosi \& Cavara) deposited in the database were also used as an outgroup. Multiple sequence alignments were carried out using the FFT-NS-i strategy of MAFFT version 6 (Katoh et al. 2002). The alignments of all sequences were further optimized manually, and gaps were deleted. A phylogenetic tree was constructed from sequences of the six genes combined by maximum likelihood (ML) methods using shotgun searches with RAxML version 8 (Stamakakis 2014). The search was repeated until the maximum likelihood was identified. Base composition homogeneity tests were conducted using Kakusan4 (Tanabe 2011). The model: GTR + Gamma was used in the tree searches. The reliability of the inferred tree was estimated by bootstrap analysis (Felsenstein 1985) repeated 100 times. Another ML tree was constructed with TUB2 gene partial sequences 
only to estimate the efficacy of using a single gene for the molecular identification of species belonging to RG 9-13.

Partial sequences of the TUB2 gene from the seven strains listed in Table 1 were used in "Standard Nucleotide BLAST" searches on the NCBI website (http://www.ncbi. nlm.nih.gov/blast/Blast.cgi?PAGE=MegaBlast\&PROGR $\mathrm{AM}=$ blastn\&BLAST _PROGRAMS $=$ megaBlast\&PAGE_ TYPE $=$ BlastSearch\&SHOW_DEFAULTS $=$ on\&BLAST_ $\mathrm{SPEC}=$ ) to identify species of RG 9-13 based on identity with TUB2 sequences deposited by Damm et al. (2009).

\section{Host plants of the re-identified species}

Sources for the strains registered by depositors were determined by search with the "Microorganism Search
System" on the NIAS Genebank website (http://www. gene.affrc.go.jp/databases-micro_search_en.php). Plants reported to be susceptible to the fungal strains were determined by search of the references listed on the "Detailed information of microorganism genetic resources" website [http://www.gene.affrc.go.jp/databases-micro_search_detail_en.php?maff=239500]. Plants from which deposited fungal strains were isolated as well as susceptible plants were recognized as host plants of the re-identified species to which the strains belong.

\section{Morphological observations}

Potato dextrose agar (PDA, Difco Laboratories, Detroit, MI, USA) plates were used to produce conidia.

Table 1. Re-identification of Colletotrichum strains at the NIAS Genebank (MAFFa) belonging to RG 9-13 spp.

\begin{tabular}{|c|c|c|c|}
\hline Re-identified species & Isolation sources (Host plant) ${ }^{\mathrm{b}}$ & MAFF accession $^{c}$ & Reference \\
\hline \multirow{3}{*}{ C. chlorophyti } & Ipomoea batatas & 238700 & Moriwaki et al. 2002 \\
\hline & Prunus $\times$ yedoensis & 240236 & \\
\hline & Vigna radiata & 305748 & Sato et al. 2014 \\
\hline C. circinans & Allium cepa & 237304 & Sato et al. 2012 \\
\hline C. dematium s. str. & Armeria maritima & 712331 & \\
\hline \multirow{7}{*}{ C. lineola } & Dianthus sp. & 237705 & \\
\hline & Helleborus niger & 712313,712314 & \\
\hline & Isotoma axillaris & 712332 & \\
\hline & Sanguisorba officinalis & 243332 & \\
\hline & Saponaria officinalis & 240431 & Sato et al. 2012 \\
\hline & Taraxacum officinale & 238064 & \\
\hline & Vigna angularis & 306708 & \\
\hline \multirow{5}{*}{ C. liriopes } & Erigeron philadelphicus & 238029 & \\
\hline & Gnaphalium affine & 238063 & \\
\hline & Helleborus niger & 239544 & \\
\hline & Rohdea japonica & $238703,240189,242679$ & Sato et al. 2012 \\
\hline & Rumex acetosa & 238060 & \\
\hline \multirow{7}{*}{ C. spaethianum } & Allium fistulosum & 237488,242675 & Moriwaki et al. 2002 \\
\hline & Crinum latifolium & 238702 & Sato et al. 2012 \\
\hline & Dianthus chinensis & 238023 & \\
\hline & Hosta montana & 238062,238067 & \\
\hline & Iris $\times$ germanica & $238024,238025,238026$ & Sato et al. 2012 \\
\hline & Kniphofia northiae & 238061 & \\
\hline & Polygonatum falcatum & 239500,242741 & Tomioka et al. 2008 \\
\hline C. tofieldiae & Ornithogalum umbellatum & 712333,712334 & Sato et al. 2012 \\
\hline C. trichellum & Hedera rhombea & $\begin{array}{l}237918,237991,237992, \mathbf{2 3 7 9 9 3} \\
238020, \mathbf{2 3 8 0 2 2}, 238027,410046\end{array}$ & $\begin{array}{l}\text { Moriwaki et al. } 2002 \\
\text { Sato et al. } 2012\end{array}$ \\
\hline
\end{tabular}

a) Acronym for microbe strains at the NIAS Genebank, National Institute of Agrobiological Sciences.

b) Bold names are host plants of diseases caused by the RG 9-13 spp. in Japan.

c) Profile and DNA sequences of each strain appears on the website, http://www.gene.affrc.go.jp/databases-micro_search_en.php Strains shown in bold font were re-identified based on BLASTN with $\beta$-tubulin-2 gene sequences and strains shown in normal font were based on a phylogenetic analysis with six genes/region. 
Table 1. (continued) Re-identification of Colletotrichum strains at the NIAS Genebank (MAFF ${ }^{\text {a }}$ belonging to RG 9-13 spp.

\begin{tabular}{|c|c|c|c|}
\hline Re-identified species & Isolation sources (Host plant) ${ }^{\mathrm{b}}$ & MAFF accession $^{c}$ & Reference \\
\hline \multirow{20}{*}{ C. truncatum } & Brassica rapa var. chinensis & 238716,305969 & Moriwaki et al. 2002 \\
\hline & Brassica sp. & 240540 & \\
\hline & Capsicum annuum var. annuиm & 242674,243068 & \\
\hline & Carica papaya & 241269 & \\
\hline & Cucumis sativus & 242676 & \\
\hline & Dendranthema grandiflorum & 238500 & \\
\hline & Dieffenbachia sp. & 238717 & Moriwaki et al. 2002 \\
\hline & Euphorbia pulcherrima & 239896,239897 & Sato et al. 2008 \\
\hline & Fagopyrum esculentum & 306552 & Moriwaki et al. 2002 \\
\hline & Glycine $\max$ & 239536,305754 & Moriwaki et al. 2002 \\
\hline & Hippeastrum $\times$ hybridum & 238718 & Moriwaki et al. 2002 \\
\hline & Houttuynia cordata & 238066 & \\
\hline & Hylocereus undatus & 240532 & \\
\hline & Passiflora edulis & 237989,305982 & Moriwaki et al. 2002 \\
\hline & Plumeria rubra & 240492,240494 & \\
\hline & Salsola komarovii & 726762,726763 & Kubota et al. 2011 \\
\hline & Sansevieria sp. & 238104 & \\
\hline & Solanum melongena & 240523,240525 & \\
\hline & Syngonium sp. & 240453 & Sato et al. 2012 \\
\hline & Vigna subterranea & 306411 & Moriwaki et al. 2002 \\
\hline Colletotrichum sp. $(\mathrm{F})^{\mathrm{d}}$ & Fagus crenata & 410758,410759 & Sasaki 1977 \\
\hline \multirow{2}{*}{ Colletotrichum sp. (PS) ${ }^{\mathrm{d}}$} & Prunus $\times$ yedoensis & $240235, \mathbf{2 4 0 2 3 6}$ & \\
\hline & Sanguisorba officinalis & $243333,243334,243337$ & Sugawara et al. 2012 \\
\hline Colletotrichum sp. $(\mathrm{Ra})^{\mathrm{e}}$ & Raphanus sativus & $238704-238715$ & Sato et al. 2005 \\
\hline Colletotrichum sp. (S) & Shibataea kumasaca & 239098 & \\
\hline
\end{tabular}

a) Acronym for microbe strains at the NIAS Genebank, National Institute of Agrobiological Sciences.

b) Bold names are host plants of diseases caused by the RG 9-13 spp. in Japan.

c) Profile and DNA sequences of each strain appears on the the website, http://www.gene.affrc.go.jp/databases-micro_search_en.php Strains shown in bold font were re-identified based on BLASTN with $\beta$-tubulin-2 gene sequences and strains shown in normal font were based on a phylogenetic analysis with six genes/region.

d) Belonging to the $C$. dematium species complex.

e) Belonging to the $C$. spaethianum species complex.

Mycelial discs (6 mm diameter) of 15 representative strains of each Colletotrichum species listed in Table 3 were cultured on the agar plates $\left(55 \mathrm{~mm}\right.$ in diam.) at $25^{\circ} \mathrm{C}$ under black light for 7 to 14 days. The length (1), width (w), height (h), horizontal distance from the apical tip to the peak of the convex (a) and the horizontal distance from the basal tip to the peak of the convex (b) for 20 conidia of each strain (Fig. 1) were measured using an image analyzer (Nikon Digital Sight; Nikon, Tokyo, Japan) attached to a microscope with differential interference contrast (DIC) illumination (Nikon Eclipse 80i; Nikon, Tokyo, Japan). "Outer curvature," "inner curvature," "curvature deviation" and the "height/width ratio" of the conidia were calculated with the formulae, $\mathrm{h} / \mathrm{l} \times 100,(\mathrm{~h}-\mathrm{w}) / 1 \times 100$, b/a and h/w, re- spectively, to quantify the curvature properties. The conidia of representative strains were photographed with a digital camera attached to the microscope with DIC illumination or phase contrast optics.

\section{Results}

\section{Molecular phylogenetic analyses and re-identifica- tion of strains}

A ML tree based on five gene sequences and a DNA region with a log likelihood of -12956.452967 was obtained from the phylogenetic analysis of sequences from 83 strains uploaded to the NIAS Genebank website and downloaded from the DDBJ/EMBL/GenBank databases 
Table 2. DNA sequence data ${ }^{a}$ used in this study

\begin{tabular}{|c|c|c|c|c|c|c|c|}
\hline \multirow{2}{*}{ Species } & \multirow{2}{*}{ Strain $^{\mathrm{d}}$} & \multicolumn{6}{|c|}{ DNA sequence accession number at the DDBJ/EMBL/GenBank } \\
\hline & & ITS $^{\mathrm{e}}$ & GAPDH $^{\mathrm{f}}$ & CHS- $1^{\mathrm{g}}$ & $\mathrm{HIS}^{\mathrm{h}}$ & $\mathrm{ACT}^{\mathrm{i}}$ & TUB2 $^{\mathrm{j}}$ \\
\hline C. anthrisci & CBS 125334 & GU227845 & GU228237 & GU228335 & GU228041 & GU227943 & GU228139 \\
\hline C. chlorophyti & IMI 103806 & GU227894 & GU228286 & GU228384 & GU228090 & GU227992 & GU228188 \\
\hline C. circinans & CBS 221.81 & GU227855 & GU228247 & GU228345 & GU228051 & GU227953 & GU228149 \\
\hline C. curcumae & IMI 288937 & GU227893 & GU228285 & GU228383 & GU228089 & GU227991 & GU228187 \\
\hline C. dematium s. str. & CBS 125.25 & GU227819 & GU228211 & GU228309 & GU228015 & GU227917 & GU228113 \\
\hline C. dematium s. str. & CBS 115524 & GU227826 & GU228218 & GU228316 & GU228022 & GU227924 & GU228120 \\
\hline C. fructi & CBS 346.37 & GU227844 & GU228236 & GU228334 & GU228040 & GU227942 & GU228138 \\
\hline C. lilii & CBS 109214 & GU227810 & GU228202 & GU228300 & GU228006 & GU227908 & GU228104 \\
\hline C. lineola & CBS 125337 & GU227829 & GU228221 & GU228319 & GU228025 & GU227927 & GU228123 \\
\hline C. lineola & CBS 124959 & GU227842 & GU228234 & GU228332 & GU228038 & GU227940 & GU228136 \\
\hline C. liriopes & CBS 119444 & GU227804 & GU228196 & GU228294 & GU228000 & GU227902 & GU228098 \\
\hline C. phaseolorum $1^{\mathrm{b}}$ & CBS 157.36 & GU227896 & GU228288 & GU228386 & GU228092 & GU227994 & GU228190 \\
\hline C. phaseolorum $2^{\mathrm{b}}$ & CBS 158.36 & GU227897 & GU228289 & GU228387 & GU228093 & GU227995 & GU228191 \\
\hline C. rusci & CBS 119206 & GU227818 & GU228210 & GU228308 & GU228014 & GU227916 & GU228112 \\
\hline C. spaethianum & CBS 167.49 & GU227807 & GU228199 & GU228297 & GU228003 & GU227905 & GU228101 \\
\hline C. spinaciae & CBS 128.57 & GU227847 & GU228239 & GU228337 & GU228043 & GU227945 & GU228141 \\
\hline C. tofieldiae & CBS 495.85 & GU227801 & GU228193 & GU228291 & GU227997 & GU227899 & GU228095 \\
\hline C. tofieldiae & IMI 288810 & GU227803 & GU228195 & GU228293 & GU227999 & GU227901 & GU228097 \\
\hline C. trichellum & CBS 217.64 & GU227812 & GU228204 & GU228302 & GU228008 & GU227910 & GU228106 \\
\hline C. truncatum & CBS 151.35 & GU227862 & GU228254 & GU228352 & GU228058 & GU227960 & GU228156 \\
\hline C. truncatum & CBS 345.70 & GU227867 & GU228259 & GU228357 & GU228063 & GU227965 & GU228161 \\
\hline C. verruculosum & IMI 45525 & GU227806 & GU228198 & GU228296 & GU228002 & GU227904 & GU228100 \\
\hline G. lindemuthiana & CBS 151.28 & GU227800 & GU228192 & GU228290 & GU227996 & GU227898 & GU228094 \\
\hline
\end{tabular}

${ }^{a}$ Cited from Damm et al. (2009)

b Tentatively designated by Damm et al. (2009)

${ }^{\mathrm{c}}$ C. $=$ Colletotrichum

${ }^{\mathrm{d}}$ Bold strains are type or ex-type

e Ribosomal DNA internal transcribed spacer

${ }^{f}$ Glyceraldehyde-3-phosphate dehydrogenase

${ }^{g}$ Chitin synthase 1

${ }^{\mathrm{h}}$ Histone3

i Actin

${ }^{j} \beta$-Tubulin-2

(Fig. 2). Sixty-four strains constituted clades with ex-type or reference strains of nine species revised by Damm et al. (2009): C. chlorophyti S. Chandra \& Tandon, C. circinans (Berk.) Voglino, C. dematium (Pers.) Grove sensu stricto, C. lineola Corda, C. liriopes Damm, P.F. Cannon \& Crous, C. spaethianum (Allesch.) Damm, P.F. Cannon \& Crous, $C$. tofieldiae (Pat.) Damm, P.F. Cannon \& Crous, C. trichellum (Fr.) Duke and C. truncatum (Schwein.) Andrus \& W.D. Moore, whereas 18 strains formed three additional clades without the ex-type or reference strains and the remaining single strain was placed on an isolated branch. The unidentified clades and the branch were tentatively designated as Colletotrichum sp. (F), (PS), (Ra) and (S) in this study (Table 1, Figs. 2, 3, 4).

Another ML tree based on phylogenetic analyses using TUB2 gene sequences with a log likelihood of -3342.819522 was obtained with the same strains used in the six gene/region sequence phylogenetic analysis (Fig. 3). The topology of both trees derived from TUB2 single-locus and the six-locus analyses were nearly the same except for the inseparability of $C$. dematium s. str. and C. lineola.

Six strains not examined in the phylogenetic analyses were re-identified as $C$. chlorophyti, $C$. liriopes, $C$. trichellum and C. truncatum based on BLASTN search (Table 1). 
Table 3. Conidial Morphology of Colletotrichum strains re-identified as revised species in RG 9-13 based on molecular phylogenetic analyses

\begin{tabular}{|c|c|c|c|c|c|c|c|c|c|}
\hline \multirow[b]{2}{*}{ Colletotrichum spp. } & \multirow{2}{*}{$\begin{array}{c}\mathrm{MAFF}^{\mathrm{b}} \\
\text { accession }\end{array}$} & \multirow[b]{2}{*}{$\begin{array}{c}\text { Outer } \\
\text { curvature }^{c}\end{array}$} & \multirow[b]{2}{*}{$\begin{array}{c}\text { Inner } \\
\text { curvature }^{\mathrm{d}}\end{array}$} & \multirow{2}{*}{$\begin{array}{l}\text { Curvature } \\
\text { deviation }^{\text {e }}\end{array}$} & \multirow{2}{*}{$\begin{array}{l}\text { Height/ } \\
\text { width } \\
\text { ratio }^{\text {f }}\end{array}$} & \multirow{2}{*}{$\begin{array}{l}\text { Length/ } \\
\text { width } \\
\text { ratio }^{g}\end{array}$} & \multicolumn{3}{|c|}{ Conidial size $(\mu \mathrm{m})$} \\
\hline & & & & & & & $\begin{array}{l}\text { Average } \\
\text { length }^{\mathrm{h}}\end{array}$ & $\begin{array}{l}\text { Average } \\
\text { width }^{\mathrm{i}}\end{array}$ & Range of length $\times$ width \\
\hline C. chlorophyti & 305748 & 30.9 & 12.2 & 1.37 & 1.67 & 5.44 & 23.4 & 4.3 & (17-) $20.6-28.5 \times 3.6-5.1$ \\
\hline C. circinans & 237304 & 18.4 & 3.1 & 1.06 & 1.23 & 6.79 & 22.4 & 2.9 & $20.2-25.1 \times(1.9-) 2.6-3.4$ \\
\hline C. dematium s. str. & 712331 & 21.7 & 4.9 & 1.60 & 1.30 & 6.00 & 21.9 & 3.7 & $20.2-24.9 \times 3.3-4.1$ \\
\hline C. lineola & 306708 & 19.9 & 2.9 & 2.12 & 1.18 & 5.99 & 18.4 & 3.1 & $16.6-20.0 \times 2.5-3.8$ \\
\hline C. liriopes & 242679 & 31.6 & 5.1 & 1.49 & 1.21 & 3.87 & 17.8 & 4.7 & $14.7-20.8 \times(3.4-) 4.2-5.6$ \\
\hline C. spaethianum & 238026 & 25.4 & 3.6 & 1.18 & 1.18 & 4.65 & 13.8 & 3.0 & $12.7-16.3 \times(2.2-) 2.7-3.7$ \\
\hline C. tofieldiae & 712333 & 30.4 & 3.8 & 1.16 & 1.17 & 3.87 & 13.8 & 3.6 & $\begin{array}{l}11.5-15.8(19.8) \times \\
3.1-4.3(-4.8)\end{array}$ \\
\hline C. trichellum & 238027 & 19.0 & 2.0 & 1.12 & 1.14 & 6.04 & 23.8 & 4.0 & $\begin{array}{r}21.7-25.6(-28) \times \\
3.8-4.9(-5.4)\end{array}$ \\
\hline \multirow{3}{*}{ C. truncatum } & 305969 & 29.9 & 10.8 & 1.35 & 1.58 & 5.32 & 19.4 & 3.7 & $(16.7-) 17.9-22.4 \times 2.9-4.6$ \\
\hline & 240453 & 26.3 & 14.2 & 1.21 & 2.19 & 8.41 & 20.4 & 2.5 & $\begin{array}{r}(15.9-) \begin{array}{l}18-23.2 \times \\
(1.8-) 2.1-2.8\end{array}\end{array}$ \\
\hline & 238500 & 27.2 & 14.3 & 1.72 & 2.15 & 7.92 & 22.4 & 2.9 & $21.2-25.1 \times(1.9-) 2.6-3.6$ \\
\hline \multirow{4}{*}{ Colletotrichum sp. $(\mathrm{Ra})^{\mathrm{a}}$} & 238705 & 34.8 & 14.5 & 1.17 & 1.73 & 4.99 & 19.5 & 3.9 & $16.6-21.6 \times 3.3-4.5$ \\
\hline & 238713 & 32.4 & 10.9 & 0.81 & 1.51 & 4.71 & 19.9 & 4.3 & $17.6-22.5 \times 3.6-5$ \\
\hline & 238706 & 29.6 & 10.4 & 1.22 & 1.56 & 5.31 & 21.5 & 4.1 & $18.9-24.6 \times 3.4-5$ \\
\hline & 238710 & 26.1 & 11.1 & 1.34 & 1.75 & 6.75 & 22.9 & 3.4 & $20.5-26.7 \times 2.8-4.3$ \\
\hline \multicolumn{10}{|c|}{ a) the anthracnose pathogen of Raphanus sativus var. hortensis (Sato et al. 2005) } \\
\hline \multicolumn{2}{|c|}{ b) acronym for microbe strains at the NIAS Genebank, National Institute of Agrol } & \multicolumn{8}{|c|}{ c) height/length $\times 100\left({ }^{(c)-g)}\right.$ see Fig. 1$)$} \\
\hline \multicolumn{10}{|c|}{ d) $($ height-width)/length $\times 100$} \\
\hline \multirow{2}{*}{\multicolumn{10}{|c|}{ e) horizontal distance from the basal tip to the peak of the convex/horizontal distance from the apical tip to the peak of the convex }} \\
\hline & & & & & & & & & \\
\hline \multicolumn{10}{|l|}{ g) length/width } \\
\hline c)-f) colors indicate large & & & & & & & & & \\
\hline
\end{tabular}

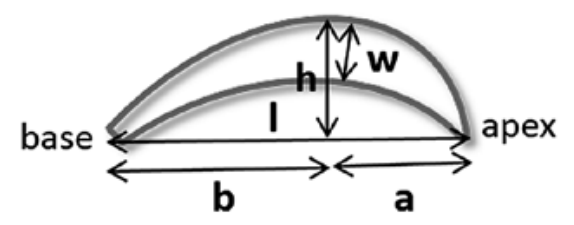

Fig. 1. Factors for calculating conidial curvature; I: length, w: width, h: height, a: horizontal distance from the apical tip to the peak of the convex, b: horizontal distance from the basal tip to the peak of the convex.

Strain MAFF 240235 had the same TUB2 sequence as that of MAFF 240236, Colletotrichum sp. (PS).

Greater than $30 \%$ of the 90 strains examined were re-identified as C. truncatum. Approximately 13, 9 and $7 \%$ were C. spaethianum, and C. lineola and C. liriopes, respectively. One or two strains corresponded to $C$. circinans, C. dematium s. str. or C. tofieldiae, whereas 12 strains pathogenic to Raphanus sativus var. hortensis formerly identified as $C$. dematium sensu lato (Sato et al. 2005) were reclassified as an unidentified species of the $C$. spaethianum complex.

\section{Host plants of the re-identified species}

Isolation sources of the re-identified strains and/or plants susceptible to the strains are listed in Table 1. References describing pathogenicity of the strains and new hosts found in this study are indicated in bold letters (Table 1). Thirty-two plant species were identified as new hosts for the seven re-identified species and two unidentified species of the RG 9-13. Of the species containing more than one strain, C. chlorophyti, C. lineola, C. liriopes, C. spaethianum, and $C$. truncatum had several host plants, whereas strains of C. tofieldiae, C. trichellum and Colletotrichum sp. $(\mathrm{F}, \mathrm{Ra})$ were isolated from single hosts. 


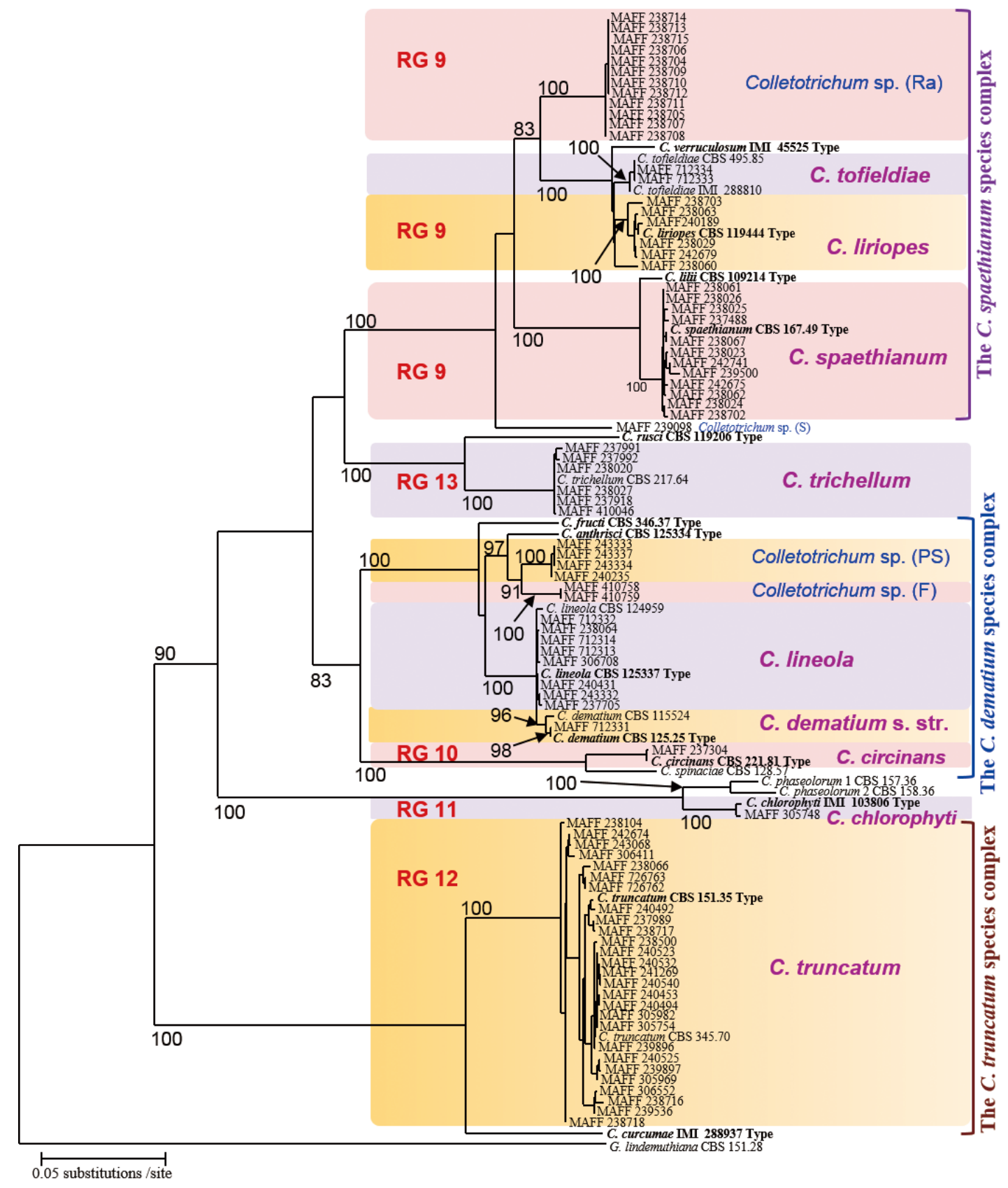

Fig. 2. Maximum likelihood tree of the rDNA-ITS region, GAPDH, CHS-1, HIS3, ACT, and TUB2 partial gene sequences of 83 Colletotrichum strains belonging to RG 9-13 spp. preserved at the NIAS Genebank (MAFF) and 23 strains comprising 19 species downloaded from the DDBJ/EMBL/GenBank databases. Numbers on the branches represent the percentage of congruent clusters in bootstrap trials repeated 100 times when the values were greater than $80 \%$. RG means "ribosomal group" proposed by Moriwaki et al. (2002) and the species complexes defined by Cannon et al. (2012)

\section{Conidial Morphology}

The conidial morphology of 15 representative strains re-identified as the nine species and Colletotrichum sp. (Ra) from Japanese radish are shown in Table 3 and Fig. 4. The conidial curvature properties, "outer curvature," "inner curvature," "curvature deviation" or "height/width ratio" in addition to sizes and length/width ratio were significantly different among the strains examined (Table 3), although values for some strains were similar to each other in terms of individual properties. The conidial curvature properties were rather consistent although some variation was found among strains of C. truncatum or Colletotrichum sp. (Ra). 


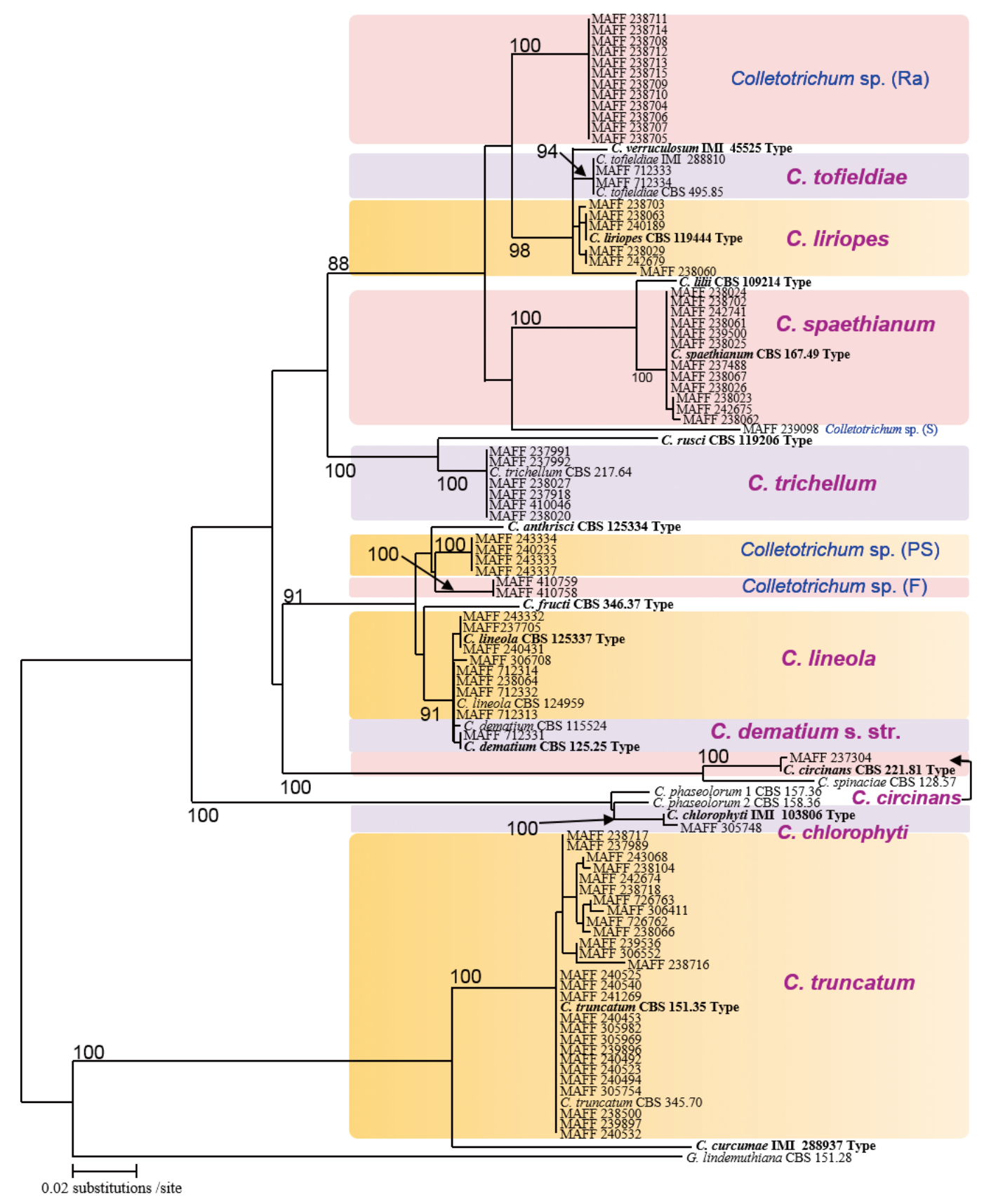

Fig. 3. Maximum likelihood tree of $\beta$-tubulin-2 partial gene sequences of Colletotrichum strains belonging to RG 9-13 spp. preserved at the NIAS Genebank (MAFF) and 23 strains comprising 19 species downloaded from the DDBJ/EMBL/ GenBank databases. Numbers on the branches represent the percentage of congruent clusters bootstrap trials repeated 100 times when the values were greater than $80 \%$.

\section{Discussion}

The nine species originally defined by Damm et al. (2009) and the four unidentified species belonging to RG 9-13 were identified in this study. The largest group, $C$. truncatum, contains 28 strains of various origins, though only five strains had been named C. truncatum prior to this study. One of the factors for strain inflation is that Colletotrichum capsici (Syd. \& P. Syd.) E.J. Butler \& Bisby, a common and global species with falcate conidia, was previously synonymized with $C$. truncatum (Damm et al. 2009). Sixteen of the 28 strains of $C$. truncatum were identified originally as C. capsici (http://www.gene.affrc.go.jp/databases-micro_search_en.php). Colletotrichum spaethianum, a species new to Japan, had twelve strains, 

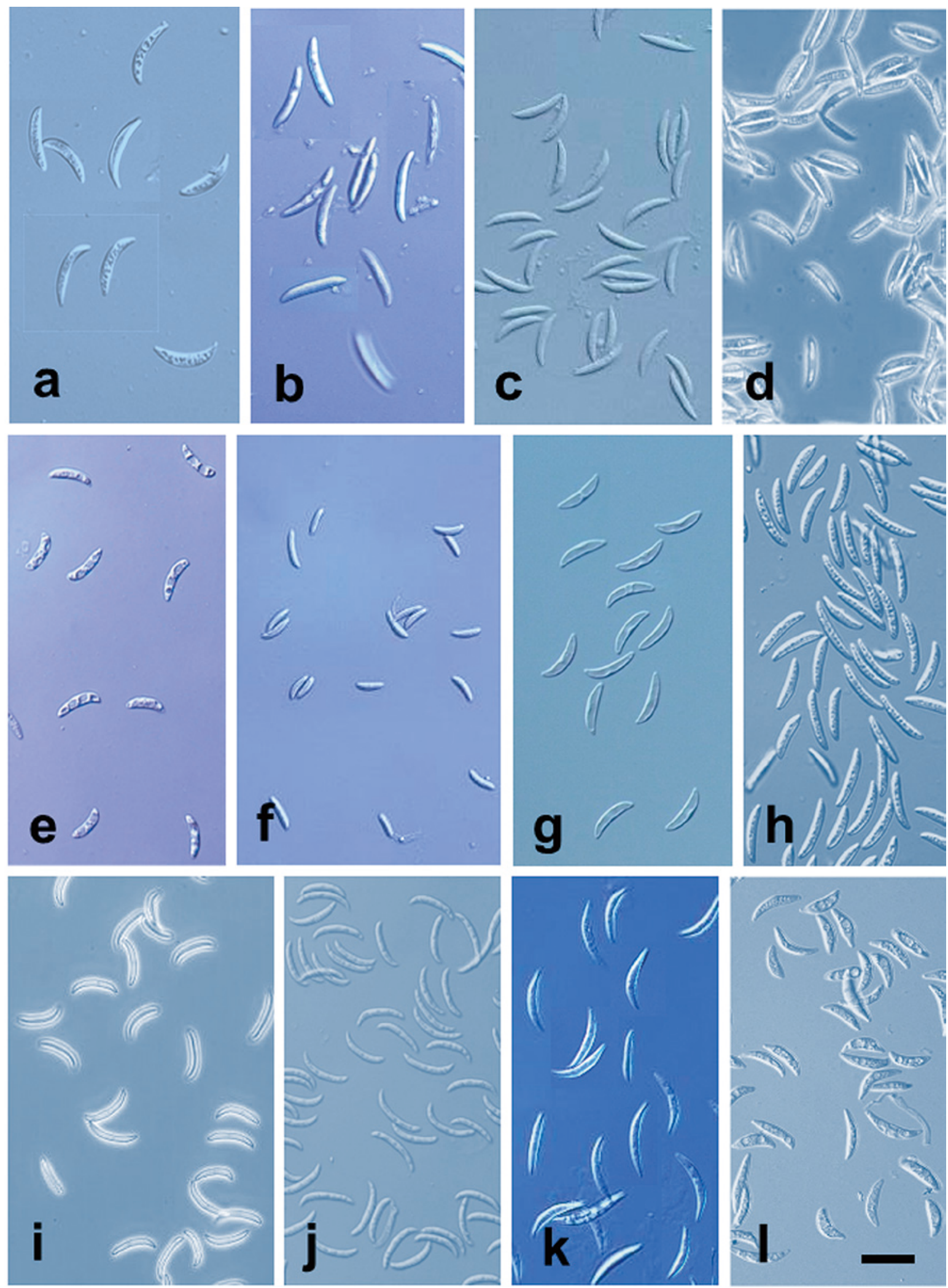

Fig. 4. Conidia of strains re-identified as revised Colletotrichum species in RG 9-13 based on the molecular phylogenetic analyses. a: MAFF 305748 (C. chlorophyti), b: MAFF 237304 (C. circinans), c: MAFF 712331 (C. dematium sensu stricto), d: MAFF 306708 (C. lineola), e: MAFF 242679 (C. liriopes), f: MAFF 238026 (C. spaethianum), g: MAFF 712333 ( $C$. tofieldiae), h: MAFF 238027 (C. trichellum), i: MAFF 240453 (C. truncatum), j: MAFF 238500 (C. truncatum), k: MAFF 238710 and I: MAFF 238706 (Colletotrichum sp. from Raphanus sativus var. hortensis), (d, i: photographed with phase contrast optics, others: with differential interference contrast (DIC) illumination, bar: $20 \mu \mathrm{m}$ ) 
of which nine were re-identified from $C$. dematium s. lato, whereas only one strain from Armeria maritima labeled as Colletotrichum sp. when deposited was identified as C. dematium s. str. (see above website). Conversely, four strains formerly named $C$. truncatum were re-identified as C. lineola in our study. Strict attention should be paid to the changes in definition of the scientific names accompanied with the splitting of RG 9-13 spp.

Colletotrichum phaseolorum S. Takim. was first described as the anthracnose pathogen of adzuki bean (Vigna angularis) in Japan. The species was once regarded erroneously as synonymous with Colletotrichum gloeosporioides (Penz.) Penz. \& Sacc., a typical species with cylindrical conidia (Arx 1957). Furthermore, Arx misspelled the name as "C. phascorum" Takimoto and cited an incorrect reference as “Ann. Phytopath. Soc. Japan 5, 21 (1934)". Two reference strains of $C$. phaseolorum, identified tentatively as "C. phaseolorum 1" and "2," were placed on branches adjacent to the clade of $C$. chlorophyti, as in the previous phylogenetic tree (Damm et al. 2009). Contrary to our expectations, MAFF 306708, a strain isolated from $V$. angularis belongs to the $C$. lineola clade (Fig. 2, 3). The authentic strains of CBS 157.36 (C. phaseolorum 1) and CBS 158.36 (C. phaseolorum 2) were isolated from Phaseolus radiatus var. aureus (adzuki bean: V. angularis at present) and Vigna sinensis (black-eyed pea: Vigna unguiculata at present), respectively, according to the CBS web catalogue. The fungus attacks $V$. unguiculata as well as $V$. angularis, as shown by reciprocal inoculations, and is also slightly pathogenic to Phaseolus vulgaris (common bean) (Takimoto 1934). The morphology and pathogenicity of MAFF 306708 should be carefully re-examined in comparison with $C$. phaseolorum.

In this study, RG 9-13 (Moriwaki et al. 2002) were connected with the latest phylogenetic taxonomy proposed by Cannon et al. (2012). They defined the C. dematium, C. spaethianum and C. truncatum species complexes for each clades consisting of closely related species reported by Damm et al. (2009). RG 9, 10 and 12 corresponded to the $C$. spaethianum, C. dematium and C. truncatum species complex, respectively, while RG 11 and 13 agreed with C. chlorophyti and C. trichellum, respectively, based on common strains used both in this study and by Moriwaki et al. (2002) (Fig. 2). Consequently, Colletotrichum sp. (Ra) belonging to RG 9 classified into the $C$. spaethianum species complex. Colletotrichum sp. (PS) and Colletotrichum sp. (F) were recognized as members of the $C$. dematium species complex because of their close relationships with the complex in the phylogram, while Colletotrichum sp. (S) seemed distinct from any of the three species complexes (Fig. 2).

The partial gene sequences for $\beta$-tubulin-2 (TUB2) were effective genetic markers for differentiation of the re-identified species of RG 9-13 except for C. dematium s. str. and $C$. lineola because phylogenetic analysis with TUB2 only clearly classified 7 species as in the 6-locus analysis. Colletotrichum dematium s. str. and C. lineola, can be distinguished not only by conidial morphology (Table 3, Fig. 4) but also by their actin, HIS3 or GAPDH sequences, as has been pointed out (Damm et al. 2009).

Thirty-two of 51 plants were new hosts for the seven re-identified species and two unidentified spp. in RG 913 found in this study. Colletotrichum chlorophyti, $C$. lineola, C. liriopes, C. spaethianum, and C. truncatum were regarded as polyphagous because of their wide host ranges. Caryophyllaceous and iridaceous plants in addition to liliaceous plants were found to be hosts of C. spaethianum in this study, though Damm et al. (2009) noted only a few liliaceous plants infected by the species. More than $30 \%$ of the 90 strains examined were re-identified as C. truncatum, a species known as an anthracnose pathogen predominately of leguminous and solanaceous plants (Damm et al. 2009). In contrast, C. trichellum and Colletotrichum sp. (Ra) appeared to be pathogenic to single hosts, Hedera rhombea and Raphanus sativus var. hortensis, respectively, because many strains of the former with diverse origins were isolated from a single plant species. The latter were obtained from two areas and found to demonstrate strong pathogenicity to Japanese radish (Sato et al. 2005). Two strains of Colletotrichum sp. (F) isolated from Fagus crenata seemed to be host specific to the tree, although this fungus was reported to be virulent to $F$. crenata seedlings only when the environment was not suitable for growth (Sasaki 1977). One strain each of Colletotrichum circinans and C. dematium s. str. was found in this study. Furthermore, C. tofieldiae that had two strains of the same origin do not have a narrow host range since the strains were reported or isolated from other plants (Damm et al. 2009). Colletotrichum sp. (PS) consisting of strains from Prunus $\times$ yedoensis and Sanguisorba officinalis is probably compatible with rosaceous plants since the latter plant became diseased after inoculation with the strains (Sugawara et al. 2012). Colletotrichum sp. (S), placed on an isolated branch, was isolated from Shibataea kumasaca, an endemic small bamboo of Japan (Ohwi \& Kitagawa 1983). The unidentified fungal species might be specialized in association with the host species.

The conidial curvature properties, especially "outer curvature," "inner curvature" and "height/width ratio" successfully represented the nature of the conidial shape. These curvature properties were stable within species as shown in the cases of C. truncatum and Colletotrichum sp. (Ra) as well as often different in combination of the parameters among the species (Table 3, Fig. 4). The re-identified species of RG 9-13 in Japan were classified into three groups with characteristics of the conidial curvature properties as follows:

1. All large outer curvature $(>25)$, inner curvature $(>10)$ 
and height/width ratio (>1.5): C. chlorophyti, C. truncatum, Colletotrichum sp. (Ra)

2. Large outer curvature $(>25)$, small inner curvature $(<6)$ and small height/width ratio $(<1.4)$ : C. liriopes, C. spaethianum, C. tofieldiae

3. All small outer curvature $(<23)$ and inner curvature $(<6)$ and height/width ratio $(<1.4)$ : $C$. circinans, $C$. dematium, C. lineola, $C$. trichellum

Groups 1, 2 and 3 defined above are obviously correlated with the $C$. truncatum, $C$. spaethianum and $C$. dematium species complex, respectively, because the reidentified species are common with each other except for C. chlorophyti and C. trichellum belonging to none of the species complexes (Fig. 2).

The conidial curvature properties should be examined in more strains than the 15 representative and in the revised species not found in this study (Damm et al. 2009). The quantified phenotypes newly characterized by this study probably more clearly describe the morphological characteristics of the revised species than any other parameter examined to date. It is also worth confirming phylogenetic implications of the curvature properties.

\section{Acknowledgements}

We are grateful to Dr. Takao Kobayashi, formerly of the Tokyo University of Agriculture, Dr. Keiichi Motohashi of the Tokyo University of Agriculture, Dr. Kei Sugawara, Yamagata Prefectural Agricultural Technique Improvement Research Office, Dr. Kunihei Kishi, Zenkoku Noson Kyoiku Kyokai Co. Ltd., Dr. Masaharu Kubota, NARO Institute of Vegetable and Tea Science (NIVTS), Dr. Keisuke Tomioka, NARO Western Region Agricultural Research Center (NARO/WARC) for depositing valuable strains of RG 9-13 spp. at the NIAS Genebank; Ms. Hiromi Nakajima, Ms. Yoshimi Igaki and Ms. Chieko Kanazawa, National Institute of Agrobiological Sciences, for their assistance in preparing and culturing the fungal strains.

\section{References}

Anonymous: Search Index Fungorum, Index Fungorum, 2014. http://www.indexfungorum.org/names/Names.asp

Arx, J. A. von (1957) Die Arten der Gattung Colletotrichum Cda. Phytopathol. Z. 29: 413-468.

Arx, J. A. von (1981) The genera of fungi sporulating in pure culture. 3rd ed. J. Cramer, Vaduz, Germany, p.315

Arx, J. A. von (1987) Plant pathogenic fungi. J. Cramer, Berlin Germany, p.288.

Cannon P. F. et al. (2012). Colletotrichum - current status and future directions. Stud. Mycol. 73, 181-213.

Carbone, I. \& Kohn, L. M. (1999) A method for designing primer sets for speciation studies in filamentous ascomycetes.
Mycologia 91, 553-556.

Corda A. K. J. (1831) Colletotrichum lineola Corda. In Sturm, Deutschland von Flora, 3 Abt. (Pilze von Deutschland) 3(12): 41.

Crouch, J. A. et al. (2009) Systematic analysis of the falcatespored graminicolous Colletotrichum and a description of six new species of the fungus from warm season grasses. Mycologia 101, 717-732.

Crous, P. W. et al. (2004) Calonectria species and their Cylindrocladium anamorphs: species with sphaeropedunculate vesicles. Stud. Mycol. 50, 415-430.

Damm, U. et al. (2009) Colletotrichum species with curved conidia from herbaceous hosts. Fungal Divers. 39, 45-87.

Felsenstein, J. (1985) Confidence limits on phylogenies: an approach using the bootstrap. Evolution 39, 783-791.

Glass, N. L. \& Donaldson, G. (1995) Development of primer sets designed for use with CR to amplify conserved genes from filamentous ascomycetes. Appl. Environ. Microb. 61, 1323-1330.

Guerber, J. C. et al. (2003) Characterization of diversity in Colletotrichum acutatum sensu lato by sequence analysis of two gene introns, mtDNA and intron RFLPs, and mating compatibility. Mycologia 95, 872-895.

Katoh, K. et al. (2002) MAFFT: a novel method for rapid multiple sequence alignment based on fast Fourier transform. Nucleic Acids Res. 30, 3059-3066.

Kubota, M. et al. (2011) Anthracnose of salt-wort (Salsola komarovii) caused by Colletotrichum truncatum. J. Gen. Plant Pathol. 77, 68-71.

Moriwaki, J. et al. (2002) Grouping of Colletotrichum species in Japan based on rDNA sequences. J. Gen. Plant Pathol. 68, 307-320.

O’Donnell, K. \& Cigelnik, E. (1997) Two divergent intragenomic rDNA ITS2 types within a monophyletic lineage of the fungus Fusarium are nonorthologous. Mol. Phylogenet. Evol. 7, 103-116.

Ohwi, J. \& Kitagawa, M. (1983) New Flora of Japan, a revised edition of phanerogam. Shibun-do, Tokyo, Japan, p.105. [In Japanese]

Sasaki, K. (1977) Materials for the fungus flora of Japan (26). Trans. Mycol. Soc. Japan 18, 343-345.

Sato, T. et al. (2005) Anthracnose of Japanese radish caused by Colletotrichum dematium. J. Gen. Plant Pathol. 71, 380-383.

Sato, T. et al. (2008) Anthracnose of poinsettia (Euphorbia pulcherrima Willd.) caused by Colletotrichum capsici. Shikoku Shokubutu Boueki Kenkyu (Proc. Assoc. P1. Protec. Shikoku) 43, 1-6. [In Japanese with English summary]

Sato, T. et al. (2012) Molecular phylogenetic analyses and morphological re-examination of strains belonging to three rare Colletotrichum species in Japan, Microbiol. Culture Collect. 28, 121-134.

Sato, T. et al. (2014) Fungi isolated from spoiled bean sprouts in Japan JARQ 48, 317-329. 
Stamatakis, A. (2014) RAxML Version 8: A tool for Phylogenetic Analysis and Post-Analysis of Large Phylogenies. Bioinformatics, 30, 1312-1313.

Sugawara, K. et al. (2012) Colletotrichum sp. with falcate conidia isolated from anthracnose lesion of great burnet. Jpn. J. Phytopathol. 78, 67-68. [In Japanese]

Sutton, B. C. (1980) The Coelomycetes. Commonwealth Mycological Institute, Kew, UK, 523-537.

Sutton, B. C. (1992) The genus Glomerella and its anamorph Colletotrichum, In Bailey, J.A. \& Jeger, M.J. (eds.), Colletotrichum: Biology, Pathology and Control, CAB International, Waningford, UK, 1-26.

Takimoto, S. (1934) A New Anthracnose of Azuki Bean. Ann. Phytopath. Soc. Jpn. 4, 21-24.

Tanabe, A. S. (2011) Kakusan4 and Aminosan: two programs for comparing nonpartitioned, proportional and separate models for combined molecular phylogenetic analyses of multilocus sequence data. Molecular Ecology Resources 11, 914-921.

The Phytopathological Society of Japan \& National Institute of Agrobiological Science (eds) (2012) Common names of plant diseases in Japan. The Phytopathological Society of Japan, Tokyo, p.1524. [In Japanese]

Tode, H. J. (1790) Fungi Mecklenburgenses Selecti. 1:1-47.

Tomioka, K. et al. (2008) Anthracnose of Polygonatum falcatum caused by Colletotrichum dematium. J. Gen. Plant Pathol. 74, 402-404.

White, T.J. et al. (1990) Amplification and direct sequencing of fungal ribosomal RNA genes for phylogenetics. In Innis, M.A., Gelfand, D.H., Sninsky, J.J. \& White, T.J. (eds.), $P C R$ Protocols: A Guide to Methods and Applications. Academic Press, San Diego, USA, 315-322. 